\title{
Meningoencephalitis, communicating hydrocephalus, drug reaction with eosinophilia and systemic symptoms (DRESS) and dengue infection in an HIV patient, Sri Lanka
}

\author{
Dr K Wirasinghe ${ }^{1}$, Dr UIP Gallage ${ }^{2}$, Dr WSC Dileka ${ }^{3}$, Dr WCJK Jayakody ${ }^{4}$
}

\begin{abstract}
Drug reaction with eosinophilia and systemic symptoms (DRESS) is a potentially life threatening, rare drug hypersensitivity reaction. Here, we present a case of meningoencephalitis, communicating hydrocephalus in a person living with HIV (PLHIV) who developed DRESS syndrome and dengue infection.
\end{abstract}

Key words: Meningoencephalitis, Communicating Hydrocephalus, Drug reaction with eosinophilia and systemic symptoms (DRESS), Dengue infection, HIV, Sri Lanka.

Authors: ${ }^{1}$ Dr K Wirasinghe (MBBS, PgD Ven), Registrar in Venereology, national STD AIDS control programe, De Saram Place, Colombo 10, Sri Lanka, ${ }^{2}$ Dr UI Gallage (MBBS, PgD Ven), Registrar in Venereology, NSACP, De Saram Place, Colombo 10, Sri Lanka.; ${ }^{3}$ Dr WSC Dileka (MBBS, PgD Ven, MD), Assistent Venereologist, NSACP, De Saram Place, Colombo 10, Sri Lanka. ${ }^{4}$ Dr WC JK Jayakody (MBBS, PgD Ven, MD), Consultant Venereologist, NSACP, De Saram Place, Colombo 10, Sri Lanka.

Corresponding author: ${ }^{1} \operatorname{Dr} K$ Wirasinghe, Email: wirasinghekanchana@gmail.com

Acknowledgement: DrJKW. Akarawita (Consultant Dermatologist, National hospital, Sri Lanka), Dr KN Wijewickrama, Senior registrar in Venereology, national STD AIDS control program, Colombo, Sri Lanka Conflict of interest: Authors claim no conflicts of interests

Funding: No funding support

Originality: This is an original article; there have been no previous publications.

\section{Full article}

\section{Introduction}

Drug reaction with eosinophilia and systemic symptoms syndrome (DRESS) is a potentially life threatening, rare drug hypersensitivity reaction which results in a skin eruption, eosinophilia and systemic symptoms due to involvement of internal organs such as liver, lungs, kidney, central nervous system (CNS), lymphatic system and heart. It usually has a long latency period such as 2 to 8 weeks. Cotrimoxazole (trimethoprim-Sulfamethoxazole) is a known drug which can cause DRESS. (1) Cotrimoxazole is frequently used as pneumocystis pneumonia (PCP) prophylaxis in HIV positive patients who have CD4 counts below 350 cells $/ \mu$ l. INAH prophylaxis of $300 \mathrm{mg}$ daily for tuberculosis given for 6 months is started in all people living with HIV prior to starting antiretroviral therapy (ART) as per WHO guidelines. There is no available literature regarding the incidence of DRESS among HIV positive patients. In 2018, estimated HIV prevalence in Sri Lanka was $0.02 \%$. (2) Meningoencephalitis in PLHIV can be the result of a viral, bacterial, parasitic, fungal or HIV unrelated pathologies. HIV is not known to infect neurons, but causes neuronal death due to indirect ways. Therefore, distinct from other types of viral encephalitis, HIV does not itself acutely present with meningoencephalitis. (3) DRESS syndrome can also have central nervous system complications such as meningoencephalitis. (1)

\section{Case report}

Forty years old male was diagnosed to have HIV infection in Jan 2019. He was asymptomatic on presentation and following exclusion of opportunistic infections and active tuberculosis (TB) he was commenced on INAH prophylaxis for TB and co-trimoxazole prophylaxis for PCP in February 2019. He was started on tenofovir, emtricitabine and 
efavirenz (TDF+FTC+EFV) regimen 2 weeks after starting INAH prophylactic therapy. Four weeks after starting Co-trimoxazole, he developed fever with chills and rigors and generalized pruritic macular papular rash (Figure 1) and elevated liver functions were noticed. But he was not dyspneic, jaundiced or pale. His blood pressure was $120 / 70 \mathrm{mmHg}$. All systemic examinations were normal. He was hospitalized and all the drugs were withheld due to the reaction. While in the hospital, his ALT was rising from $44 \mathrm{IU} / \mathrm{I}$ to 2,666 IU/l; AST to $271 \mathrm{IU} / \mathrm{l}$; total bilirubin was $66.5 \mathrm{IU} / \mathrm{I}$ and direct bilirubin increased to $63.1 \mathrm{IU} / \mathrm{I}$. His eosinophil count rose to $9.3 \%$. His total WBC was $6.87 \times 10^{3}$ cells $/ \mu$ l (reference range 4-10) with an absolute eosinophil count of $0.68 \times 10^{3}$ cells $/ \mu$ l (reference range 0.02-0.5). He was clinically diagnosed to have DRESS syndrome by the consultant dermatologist. He was treated with oral chlorpheniramine, prednisolone $30 \mathrm{mg}$ twice daily tapering off dose, betamethasone local application and was monitored for hepatic encephalopathy. He was continuing to have daily high fever spikes for initial 12 days without any evidence of underlying infections. He was discharged after 19 days of hospital stay following settling of his fever and normalization of liver transaminases. He was restarted on TDF, FTC, raltegravir (RAL) regimen and it was withheld one month later due to increasing liver transaminases. Even though there were few attempts to reintroduce ART, it failed due to his rising liver enzymes.

He was again hospitalized in September 2019 with fever, persistent erythematous rash and low platelets. He was managed as dengue fever with his positive dengue NS1 antigen and dropping platelet count. He was discharged after 10 days of the hospital admission once he became stable. Two days after the discharge he was readmitted with fever, photophobia, headache, and confusion with a GCS of 13/15 without any focal neurological signs. Fundal examination was normal. Respiratory system was normal with no crepitations or rhonchi. Blood pressure was $116 / 86 \mathrm{mmHg}$ and pulse rate was $120 / \mathrm{min}$. Abdominal examination was normal. A full opportunistic infection screening was repeated (table 1 , table 2 , table 3 ). Non- contrast computer-tomography (NCCT) brain was normal at admission. Lumbar puncture was done (table 2) and revealed neutrophil pleocytosis and gram positive diplococci. Antimeningetic doses of antibiotics IV merapenum $2 \mathrm{~g}$ 8hrly and IV vancomycin $500 \mathrm{mg} 6$ hrly was given. Empirically oral valgancyclovir $900 \mathrm{mg}$ was started. Patient's conscious level improved initially with antibiotics, but it was deteriorated on third day rapidly and the high fever spikes were continued. Urgent MRI brain revealed communicating hydrocephalus and basal meningeal enhancement without any focal lesions. External ventricular drainage was inserted and CSF was sent for investigations (table 2) to diagnose underlying cause for having non resolving meningoencephalitis with communicating hydrocephalus. There were fluctuations in his serum sodium which was initially $133 \mathrm{mmol} / \mathrm{l}$ and went down to 120 $\mathrm{mmol} / \mathrm{l}$ but later it became normalized with hypertonic saline. His serum potassium level remained normal. His urinary sodium level, potassium level, urine osmolality, serum osmolality and urine to serum osmolality ratio was normal. His blood urea and creatinine level remained normal with $0.83 \mathrm{mg} / \mathrm{dl}$ an eGFR of $110 \mathrm{ml} / \mathrm{min} / 1.73 \mathrm{~m} 2$. Persistently his GCS was less than 8 , pupils being sluggishly reactive, $4 \mathrm{~mm}$ in size with bilateral extensor plantar reflex and in decerebrate position.

The repeat CSF report became positive for Toxoplasma antibodies IgM and IgG CSF Toxoplasma titres were not done due to unavailability. Although confirmatory test, CSF T.gondii PCR was lacking, it was decided to give a trial of anti-toxoplasmosis therapy. $\mathrm{He}$ was started empirically on pyrimethamin $200 \mathrm{mg}$ loading dose, followed by $50 \mathrm{mg}$ oral daily, intravenous clindamycin $600 \mathrm{mg} 6$ hourly, folinic acid $10 \mathrm{mg}$ orally. Sulfadiazine was replaced by clindamycin due to increased risk of drug reactions. Though his fever subsided the day following the antibiotics, there was no clinical improvement. The repeat MRI revealed periventricular enhancement even though the hydrocephalus settled, patient subsequently succumbed to death. 
Table 1: HIV related investigations

\begin{tabular}{|c|c|c|}
\hline Investigations & $\begin{array}{l}\text { Pre ART } \\
\text { screening of } \\
\text { Opportunistic } \\
\text { infections } \\
\text { January } 2019\end{array}$ & $\begin{array}{l}\text { In ward } \\
\text { opportunistic } \\
\text { screening } \\
\text { September to } \\
\text { October } 2019\end{array}$ \\
\hline CD4 & 262 cells/ $\mu l$ & 31 cells/ $\mu$ l \\
\hline Viral load & $\begin{array}{r}29100 \text { copies/ } \\
\mu \mathrm{l}\end{array}$ & \\
\hline CMV IgM- & Negative & Equivocal \\
\hline CMV IgG & Negative & Positive \\
\hline S.CMV PCR & & Negative \\
\hline $\begin{array}{l}\text { S.cryptococcal - } \\
\mathrm{Ag}\end{array}$ & & Negative \\
\hline HBsAg & Negative & Negative \\
\hline $\begin{array}{ll}\text { Hepatitis } & \text { C } \\
\text { antibodies } & \end{array}$ & Negative & Negative \\
\hline Hepatitis A IgM & & Negative \\
\hline Hepatitis A IgG & & Positive \\
\hline EBV IgG & & Positive \\
\hline $\begin{array}{l}\text { Serum } \\
\text { Toxoplasma IgM }\end{array}$ & Negative & Positive \\
\hline $\begin{array}{l}\text { Serum } \\
\text { Toxoplasma IgG }\end{array}$ & Negative & Positive \\
\hline $\begin{array}{l}\text { Sputum TB gene } \\
\text { Xpert culture }\end{array}$ & Negative & \\
\hline $\begin{array}{ll}\text { Sputum } \\
\text { culture }\end{array}$ & Negative & \\
\hline VDRL/TPPA & Negative & Negative \\
\hline
\end{tabular}

Figure 1. Generalized, symmetrical, pruritic, macular papular rash
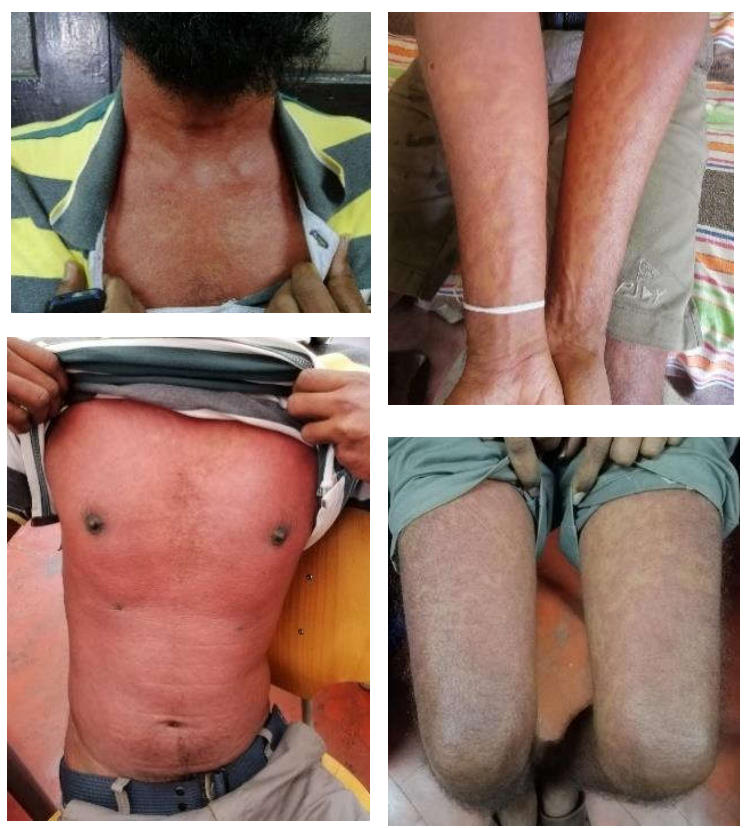

Figure 2. MRI brain. Showing sub-acute meningitis complicated with communicating Hydrocephalus and basal meningeal enhancement without any focal lesions
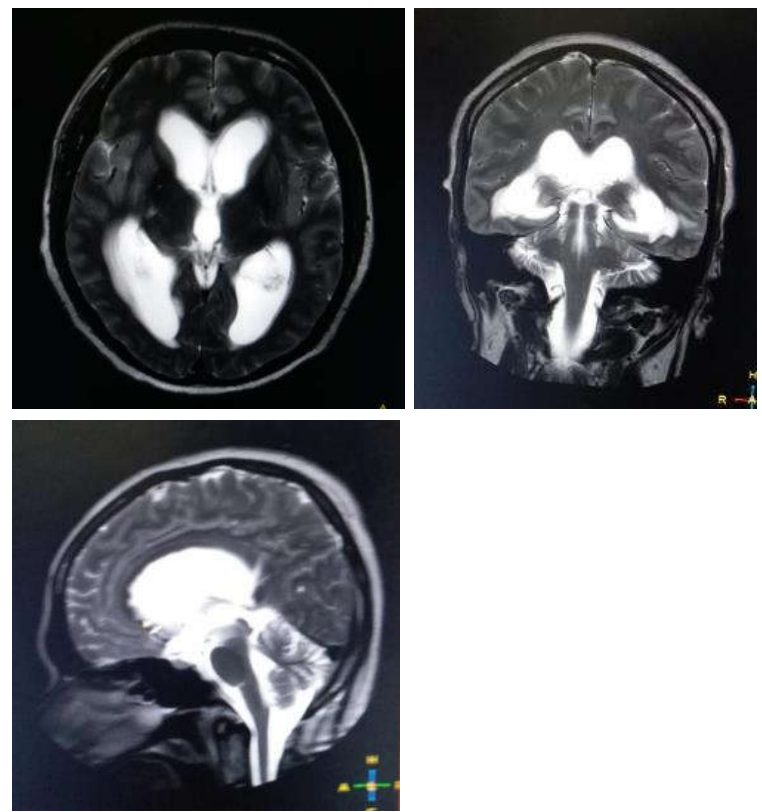

Figure 3. NCCT brain, showing marked hydrocephalus and brain edema

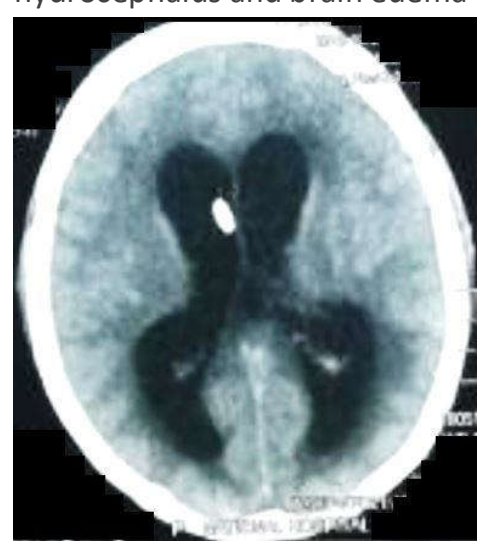

Table 2: CSF investigations

\begin{tabular}{|l|r|}
\hline CSF & Result \\
\hline Color & Colorless \\
\hline Appearance & Slightly cloudy \\
\hline Protein & $57 \mathrm{mg} / \mathrm{dl}$ \\
\hline Glucose & $46 \mathrm{mg} / \mathrm{dl}$ \\
\hline WBC & $513 \mathrm{~mm} 3$ \\
\hline Neutrophils & $80 \%$ \\
\hline Lymphocytes & $20 \%$ \\
\hline RBC & 73 \\
\hline Organisms & Gram positive diplococci seen \\
\hline CSF culture & No growth \\
\hline CSF cryptococcal Ag & Negative \\
\hline EBV IgG & Detected \\
\hline VDRL/TTPA & Negative \\
\hline TB Gene Expert & Not detected \\
\hline
\end{tabular}




\begin{tabular}{|l|l|}
\hline TB culture & \\
\hline CMV IgM & Equivocal \\
\hline CMV IgG & Negative \\
\hline CMV PCR & Not detected \\
\hline VZV & No detected \\
\hline Enterovirus & Not detected \\
\hline
\end{tabular}

Table 3: Inward investigations

\begin{tabular}{|c|c|c|}
\hline Investigation & $\begin{array}{l}\text { In ward } \\
\text { investigations } \\
\text { done during } \\
\text { dengue } \\
\text { admission } \\
\text { (Sept 2019) }\end{array}$ & $\begin{array}{l}\text { In ward } \\
\text { investigations } \\
\text { done during } \\
\text { last medical } \\
\text { admission (Oct } \\
\text { 2019) }\end{array}$ \\
\hline CXR & Normal & Normal \\
\hline 2D echo & Not done & $\begin{array}{l}\text { No infective } \\
\text { endocarditis }\end{array}$ \\
\hline $\begin{array}{l}\text { Coagulation } \\
\text { profile INR } \\
\text { APTT } \\
\text { PT }\end{array}$ & Normal & $\begin{array}{r}0.93 \text { (normal) } \\
22 \text { (normal) } \\
10.6 \mathrm{sec} \\
\text { (normal) }\end{array}$ \\
\hline Blood picture & $\begin{array}{r}\text { Features } \\
\text { compatible } \\
\text { with viral } \\
\text { infection }\end{array}$ & $\begin{array}{r}\text { no features of } \\
\text { micro } \\
\text { angiopathic } \\
\text { hemolytic } \\
\text { anemia, no } \\
\text { malignant cells }\end{array}$ \\
\hline AST & $568 \mathrm{IU} / \mathrm{I}$ & $51 \rightarrow 71 \mathrm{U} / \mathrm{I}$ \\
\hline ALT & $827 \mathrm{IU} / \mathrm{I}$ & $44 \rightarrow 2,666 \mathrm{U} / \mathrm{I}$ \\
\hline Total Bilirubin & Normal & 66.5 \\
\hline Direct Bilirubin & Normal & 63.1 \\
\hline Albumin & Normal & 26 \\
\hline Globulin & Normal & 29 \\
\hline CRP & 10 & $45 \mathrm{mg} /$ \\
\hline ESR & $97 \mathrm{~mm}$ & \\
\hline Platelets & $131 \times 103$ & $155 \times 103$ \\
\hline Blood Culture & Negative & Negative \\
\hline Urine culture & Negative & Negative \\
\hline
\end{tabular}

\section{Discussion}

Management of HIV infection had drastically improved during the last decade due to advent of ART and standardized and prompt management of opportunistic infections (Ols). But the use of ART and medications for Ols can be limited because of the adverse effects and hypersensitive reactions caused by these medications. This patient was diagnosed to have DRESS possibly due to co-trimoxazol. This was considered since there was the latency period between drug exposure and onset of symptoms in DRESS syndrome when compared to INAH and EFV. DRESS syndrome is described to have a long latency period of 2 to 8 weeks after exposure to a possible drug. DRESS syndrome was first described to be caused by sulphonamide containing drugs but later antiepileptic drugs such as phenytoin, carbamazepine, lamotrigine, phenobarbital and allopurinol were frequently reported causes.(1) This case points to an instance where the clinicians could not continue the patient on ART due to possible DRESS syndrome and development of subsequent opportunistic infections as a result of severe immune deficiency.

Drug reaction with eosinophilia and systemic symptoms is a drug induced, rare, but potentially life-threatening hypersensitivity reaction which manifests with skin eruptions, hematological abnormalities like eosinophilia, atypical lymphocytosis, lymphadenopathy and internal organ involvement (Lung, Liver, Kidney). (4)

As the diagnosis of DRESS is based on clinical judgment with high degree of suspicion, the European Registry of Severe Cutaneous Adverse Reactions (RegiSCAR) has developed a scoring system, by which DRESS can be classified as definite, probable or possible disease. (5) According to this classification, our patient who had been exposed to high risk medications, namely, Cotrimoxazole, Isoniazide and Efaviranz two to four weeks prior to the onset of symptoms, had fever > $38.5{ }^{\circ} \mathrm{C}$, eosinophilia of $>9 \%$ with an absolute eosinophil count of $0.68 \times 10^{3}$ cells $/ \mu \mathrm{l}$ (reference range 0.02-0.5), rash involving > $50 \%$ of body surface area, involvement of one organ (liver) and disease duration of more than 15 days had "probable DRESS" with a score of 5.

The patient could not be continued on ART as his liver transaminases started rising drastically, despite being attempted twice with least hepatotoxic regimens of TDF, FTC and RAL combination. One possible reason for elevation of liver enzymes with reintroduction of ART could be due to FTC and RAL which are known to cause drug induced hepatitis as well. Another reason could be drug hypersensitivity reaction due to RAL which is a rare cause for drug hypersensitivity reactions. (6) 
The patient developed the next episode of fever with positive dengue NS1 antigen when the patient was off ART and was on a tapering off dose of prednisolone for DRESS. He had the persistent erythematous rash following the diagnosis of DRESS syndrome. Even though DRESS can have a relapsing course, with the positive dengue NS1 antigen and thrombocytopenia, the patient was treated as for dengue fever. Even though Dengue NS1 antigen has a specificity of $89.1 \%$ in diagnosing dengue fever, the dengue epidemic in the countryand the rising platelet count with settling fever established the diagnosis of dengue fever in the first admission in September. (7) On the other hand missed opportunity of diagnosing possible opportunistic infections with 6 days of hospital admission and attribution of whole picture to dengue fever is a diagnostic dilemma in this case.

Two days following discharge the patient was readmitted with fever, photophobia, headache and confusion. There were no signs to suggest meningism. The initial NCCT being normal and CSF report with slightly high proteins and neutrophil pleocytosis with gram positive diplococci made the diagnosis of bacterial meningitis and commenced on meningitic doses of antibiotics, Intra venous meropenum intravenous vancomycin and intravenous acyclovir was empirically started. However, patient's condition progressively deteriorated despite treatment. Communicating hydrocephalus and basal meningeal enhancement without any focal lesions were clearly evident from the subsequent MRI scan, which suggests poor prognosis. Hence it can be inferred that the initial disease diagnosis was suboptimal.

In an HIV infected patient presenting with CNS symptoms, the most important factor in differentiating the diagnosis is the degree of immune suppression of the patient. (8) Having CD4 cell count of 31cells/ $\mu$ l signify a marked immunosuppression and most likely diagnoses are AIDS associated tumors and opportunistic infections. The leading considerations are Toxoplasma encephalitis, primary CNS lymphoma, progressive multifocal leukoencephalopathy, HIV encephalopathy,
CMV encephalitis and cryptococcal meningitis. CNS tuberculosis infection also must be considered in our setting where TB is common.

Ventricular enlargement, meningeal enhancement in MRI scan with slightly elevated CSF proteins with positive CMV IgG suggested CMV encephalitis although it was very rare and commenced on IV gangcyclovir on day 7 of admission. Even though, CSF CMV PCR report is negative possibility of CMV encephalitis could not be excluded.

Toxoplasmosis being the commonest $\mathrm{Ol}$ in the central nervous system (CNS), was suspected in this patient as the patient was not on cotrimoxazole prophylaxis and it was suspected to be the culprit drug for his DRESS syndrome. Absence of the typical clinical and radiological findings and the initial negative toxoplasma IgG and very high liver transaminase and bilirubin levels with impending liver failure and DRESS syndrome made us reluctant to start toxoplasma treatment empirically.

The patients with toxoplasma encephalitis are uniformly seropositive for anti-toxoplasma IgG and the absence of it makes the diagnosis unlikely. Further, it usually presents with focal neurological signs due to multiple ring enhancing lesions giving rise to mass effect localized in the parietal and frontal lobes, in the thalamus or basal ganglia or in the corticomedullary junction. (9) Multiple ring enhancing lesions with mass effect are visible after injection of gadolinium T1-weighted MRI in about $90 \%$ of cases, rarely toxoplasma can present without focal neurological signs with diffuse encephalopathy. (10) However, when there is diffuse encephalitis, the progression is rapid, and the outcome is fatal and is a rare entity and there is limited literature available with very few case reports. (11)

Common causes for hydrocephalus in HIV/AIDS patients are primary normal pressure hydrocephalus, subarachnoid hemorrhage and meningitis. However, hydrocephalus due to toxoplasmosis, tuberculous meningitis and cryptococcal meningitis is very rare with few, reported cases in literature. (12) The mechanism of development of hydrocephalus in toxoplasma is defined as either compression of cerebro spinal fluid (CSF) pathway by 
surrounding parenchymatous space occupying lesion or blockage of CSF flow within the ventricular system and ependymal canal by an exudate from necrotizing ependymitis. Development of hydrocephalus in a patient with diffuse toxoplasma encephalitis was not been reported so far.

Even though toxoplasma encephalitis usually occurs as a reactivation of latent infection, this patient's toxoplasma IgG at the time of HIV diagnosis was negative. However, both toxoplasma IgM and IgG became positive in blood and CSF later on around day 10 of last admission. CSF toxoplasma titres were not done due to unavailability. Although CSF T.gondii PCR was lacking, it was decided to give a trial of anti-toxoplasmosis therapy. Therefore, the patient was started on the alternative regimen suspecting diffuse toxoplasma encephalitis with oral pyrimethamine, oral clindamycin with leucovorin because the definitive treatment cannot be administered due to impending DRESS syndrome.

Even though, the fever settled with the treatment, the clinical improvement was minimal due to ongoing brain damage as evident on repeat MRI, with periventricular enhancement and hydrocephalus.

Patient might have developed systemic inflammatory response syndrome (SIRS) at the end stage as it fulfilled more than two criteria such as fever for more than $38^{\circ} \mathrm{C}$, rapid heart rate of $120 / \mathrm{min}$ with blood pressure of 116/86 $\mathrm{mmHg}$. He had deep irregular breathing which was rapid and abnormal hematological indices. But his septic screening remained negative. Although his serum sodium level decreased $120 \mathrm{mmol} / \mathrm{L}$ which was corrected by hypertonic saline. His serum potassium level remained normal and there were no features of syndrome of inappropriate ADH secretion.

Cryptococcal meningitis can be excluded by negative blood and CSF findings. Even though TB investigations were normal, TB meningitis cannot be totally excluded due to several factors. Severely immunocompromised state, on long term steroids for DRESS and poor sensitivity of CSF Gene xpert and TB culture (sensitivity of 10 to $60 \%$ ).(13) Any other fungal meningoencephalitis can not be totally excluded due to lack of testing facilities.

Although atypical presentation of toxoplasma encephalitis is another high probability. The reason for atypical presentation could be the long term steroid therapy and administration of high dose steroids at the time of diagnosing dengue and bacterial meningitis. But high index of suspicion should always be in mind when treating severely immune compromised patients with fever and CNS symptoms as toxoplasmosis is one of the commonest CNS opportunistic infections. However, the possibility of drug reactions and possible liver failure made it reluctant of starting toxoplasma treatment empirically with misleading dengue fever and delaying of definitive diagnosis, finally lead to the unavoidable brain damage and death of this patient.

\section{References}

1. Roujeau JD.Drug reaction with eosinophilia and systemic symptoms (DRESS), UpToDate 2019.

2. National STD/AIDS Control programe. Elimination of Mother to Child transmission of HIV and syphilis, National Validation report, Sri Lanka. 2. National STD/AIDS Control programe, Ministry of Health. Colombo : s.n., August,2019.

3. Wendel KA, McArthur JC. Acute meningoencephalitis in chronic human immunodeficiency virus (HIV) infection: putative central nervous system escape of HIV replication. Clinical infectious diseases. 2003 Oct 15;37(8):1107-11.

4. Mockenhaupt M. Drug reaction with eosinophilia and systemic symptoms (DRESS). uptodate. 2019.

5. Kardaun $\mathrm{SH}$, Sidoroff A, Valeyrie-Allanore $L$ et al. Variability in the clinical pattern of cutaneous sideeffects of drugs with systemic symptoms: Does a DRESS syndrome really exist? $\mathrm{Br} J$ Derm. 2007;157(609).

6. CDC guidelined for use of Antiretroviral agents in adults and adolescents living with HIV 2018

7. Vaishali N Solanke, Mohan G Karmarkar PRM. Early dengue diagnosis: Role of rapid NS1 antigen, NS1 early ELISA, and PCR assay. Trop J Med Res. 2015;18(2):95-9.

8. Koralnik IJ. Approach to HIV-infected patients with central nervous system lesions. Uptodate.

9. Miller RF, Hall-Craggs MA, Costa DC, Brink NS, Scaravilli F, Lucas SB, Wilkinson ID, Ell PJ, Kendall BE HM. Magnetic resonance imaging, thallium-201 SPET scanning, and laboratory analyses for discrimination of cerebral lymphoma and toxoplasmosis in AIDS. Sex Transm Infect. 1998;74(4):258. 
10. Image $M$ ring enhancing lesions with mass effect are visible after injection of gadolinium in this $T$. Multiple ring enhancing lesions with mass effect are visible after injection of gadolinium in this T1weighted image. Clin Infect Dis. 1992;15(2):211.

11. Frangoise Gray, Romain Gherardi, Elizabeth Wingate I, Jeffrey Wingate 1, Gilles F6nelon , Andr Gaston AS, Poirier and J. Diffuse "encephalitic" cerebral toxoplasmosis in AIDS. J Neurol. 1989;236:273-7.
12. Djientcheu VDP, Njamnshi AK, Ongolo-Zogo $P$, Dongmo L, Eloundou JN, Rilliet B, et al. Hydrocephalus: A rare presentation of central nervous system toxoplasmosis in the acquired immunodeficiency syndrome. African J Neurol Sci. 2004;23(2).

13. British HIV Association guidelines for the treatment of TB/HIV Co-infection. HIV Medicine. British HIV Association guidelines.United Kingdom. 2011;12:517-537 